\title{
Preparation of Disyndiotactic Poly(methyl crotonate) by Stereospecific Group Transfer Polymerization
}

\author{
Koichi Ute, ${ }^{\dagger}$ Toshiyuki Tarao, Shin-ya Hongo, Hidetaka Ohnuma, \\ Koichi Hatada, ${ }^{\dagger \dagger}$ and Tatsuki Kitayama \\ Department of Chemistry, Graduate School of Engineering Science, \\ Osaka University, Toyonaka, Osaka 560-8531, Japan
}

(Received August 31, 1998)

\begin{abstract}
Stereospecific living polymerization of methyl crotonate was achieved by using ketene trialkylsilyl acetals as initiators in the presence of $\mathrm{HgI}_{2}$ and iodotrialkylsilanes as catalyst and co-catalysts, respectively. $\mathrm{ZnI}_{2}$ and $\mathrm{CdI}_{2}$ also catalyzed the polymerization. Disyndiotactic polymers with narrow molecular weight distribution were obtained quantitatively. Livingness and stereospecificity of this polymerization were sensitive to the structure of trialkylsilyl groups in the initiator and co-catalyst; $\left(\mathrm{C}_{2} \mathrm{H}_{5}\right)_{3} \mathrm{Si}-$ and $\left(n-\mathrm{C}_{3} \mathrm{H}_{7}\right)_{3} \mathrm{Si}-$ systems gave the active species with higher thermal stability and higher stereospecificity than $\left(\mathrm{CH}_{3}\right)_{3} \mathrm{Si}$ - system. Configurational determination of the disyndiotactic poly(methyl crotonate)s was made by chromatographic separation of their low molecular weight homologs (tetramer and hexamer), followed by X-ray single crystal analysis. The results of oligomer analysis led to the conclusion that the disyndiotactic polymer chains are formed by the threo addition of monomers to propagating chain-ends and trans opening of monomer $\mathrm{C}=\mathrm{C}$ double bonds.

KEY WORDS Methyl Crotonate / Methyl Isocrotonate / Living Polymerization / Stereoregularity Ditacticity / Oligomer / X-Ray Single Crystal Analysis /
\end{abstract}

Recently, we have found that methyl crotonate can be polymerized by the group-transfer polymerization (GTP) using 1-methoxy-1-(trimethylsiloxy)-2-methyl-1-propene (1) together with catalytic amounts of $\mathrm{HgI}_{2}$ and $\left(\mathrm{CH}_{3}\right)_{3} \mathrm{SiI}$ in $\mathrm{CH}_{2} \mathrm{Cl}_{2}$.<smiles>CC=CC(=O)OC</smiles><smiles>COC(=O)C(C)C(C)C(=O)OC</smiles>

Two useful pieces of information led to this finding; (1) the GTP of acrylates using $\mathrm{HgI}_{2}$ as a catalyst in toluene gives a good control of molecular weight, ${ }^{2,3}$ and (2) the use of $\left(\mathrm{CH}_{3}\right)_{3} \mathrm{SiI}$ as a co-catalyst and $\mathrm{CH}_{2} \mathrm{Cl}_{2}$ /toluene mixture as a solvent drastically accelerates the $\mathrm{HgI}_{2}$-catalyzed GTP of $n$-butyl acrylate. ${ }^{4,5}$

Before this finding, direct preparation of poly(methyl crotonate) from its monomer had been considered to be difficult. As a commonly observed feature of crotonates, methyl crotonate gives no polymer by a free radical mechanism. ${ }^{6,7}$ Typical anionic initiators such as alkyllithiums or Grignard reagents are ineffective for the polymerization of methyl crotonate, ${ }^{6-9}$ whereas branched alkyl crotonates including $t$-butyl and triphenylmethyl crotonates are polymerized in good yields ${ }^{6-16}$ and in a living manner ${ }^{17,18}$ by these initiators. The only compound that had been known to polymerize methyl crotonate in a substantial yield was $\mathrm{CaZn}\left(\mathrm{C}_{2} \mathrm{H}_{5}\right)_{4}$ complex. The polymerization of methyl crotonate with this complex in toluene at $-78^{\circ} \mathrm{C}$ for $96 \mathrm{~h}$ affords a polymer in $28 \%$ yield. $^{8}$

In spite of the difficulty of methyl crotonate polymerization, several kinds of poly(methyl crotonate)s with various stereoregularities have been prepared and identified in the last five years. These poly(methyl crotonate)s were derived from threodiisotactic poly(triphenylmethyl crotonate), ${ }^{13}$ diheterotactic poly( $t$-butyl crotonate), ${ }^{15}$ and atactic-like poly( $t$-butyl crotonate $)^{12}$ by means of hydrolytic cleavage of the ester functions and subsequent methylation with $\mathrm{CH}_{2} \mathrm{~N}_{2}$. The previous paper ${ }^{1}$ reported that the poly(methyl crotonate) formed by GTP showed ${ }^{1} \mathrm{H}$ NMR spectra quite different from those of threodiisotactic, diheterotactic, and atactic-like poly(methyl crotonate)s.

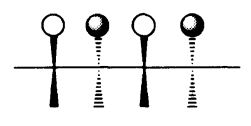

threodiisotactic

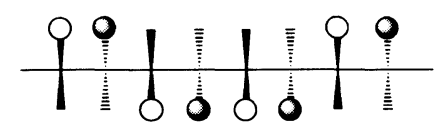

diheterotactic

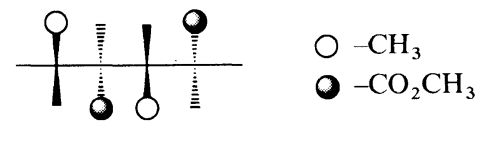

disyndiotactic

The present paper provides details of our studies on the GTP of methyl crotonate and stereostructure analysis of the resultant polymers and oligomers.

\section{EXPERIMENTAL}

\section{Materials}

Methyl crotonate purchased from Lancaster Synthesis was purified by fractional distillation (bp 118.2-

\footnotetext{
$\uparrow$ To whom correspondence should be addressed.

${ }^{\dagger}$ Present address: Fukui University of Technology, Fukui 910-8505, Japan.
} 
$119.0^{\circ} \mathrm{C} / 760$ Torr), dried over $\mathrm{CaH}_{2}$, and then vacuum distilled just before use. The chemical purity was $99.9 \%$ (the main impurity was methyl isocrotonate) by GC. Methyl isocrotonate was prepared from isocrotonic acid and $\mathrm{CH}_{2} \mathrm{~N}_{2}$, and purified in a manner similar to above (purity $97.7 \%$ ). Isocrotonic acid was synthesized according to the procedure described in the literature. ${ }^{19}$

The compound 1 was prepared by the procedure described in the literature, ${ }^{20,21}$ and purified by fractional distillation (bp $74-75^{\circ} \mathrm{C} / 61$ Torr, purity $98.8 \%$ ). 1Methoxy-1-(triethylsiloxy)-2-methyl-1-propene (2) (bp $50-51{ }^{\circ} \mathrm{C} / 2.3$ Torr, purity $97.4 \%$ ) and 1-methoxy-1(tripropylsiloxy)-2-methyl-1-propene (3) (bp 65-66 $\mathrm{C} /$ 7.0 Torr, purity $99.2 \%$ ) were prepared in a similar manner.<smiles>CCOC(OC)=C(C)C</smiles>

2<smiles>CCCCCCCOC(OC)=C(C)C</smiles>

3
$\left(\mathrm{CH}_{3}\right)_{3} \mathrm{SiI}$ purchased from Aldrich was used as received (purity $>96 \%$ by ${ }^{1} \mathrm{H}$ NMR). $\left(\mathrm{C}_{2} \mathrm{H}_{5}\right)_{3} \mathrm{SiI}$ was prepared from $\left(\mathrm{C}_{2} \mathrm{H}_{5}\right)_{3} \mathrm{SiH}$ and $\mathrm{CH}_{3} \mathrm{I}$ in the presence of $\mathrm{PdCl}_{2}$ according to the literature, ${ }^{22}$ and purified by distillation (bp $71-72^{\circ} \mathrm{C} / 17$ Torr, purity $>99 \%$ ). ( $n$ $\left.\mathrm{C}_{3} \mathrm{H}_{7}\right)_{3} \mathrm{SiI}$ was prepared and purified in a similar manner (bp $52^{\circ} \mathrm{C} / 0.48$ Torr, purity $>99 \%$ ).

$\mathrm{HgI}_{2}(99.9 \%)$ purchased from Wako Pure Chemical was dried in vacuo at room temperature for $20 \mathrm{~min}$ and used as $2 \mathrm{gl}^{-1}$ solution in dry $\mathrm{CH}_{2} \mathrm{Cl}_{2}$.

\section{Polymerization Procedure}

Polymerization was initiated by adding a solution of initiator in $\mathrm{CH}_{2} \mathrm{Cl}_{2}$ to a stirred mixture of methyl crotonate, $\mathrm{HgI}_{2}$, iodotrialkylsilane and $\mathrm{CH}_{2} \mathrm{Cl}_{2}$ under a dry nitrogen atmosphere. The reaction mixture was homogeneous throughout the polymerization. After a predetermined period of polymerization, a small amount of $\mathrm{HCl} / \mathrm{CH}_{3} \mathrm{OH}$ ( $c a .1 \mathrm{M}$ ) was added to the mixture, and then the volatile components were removed by evaporation under reduced pressure. The residue was dissolved in a mixture of $\left(\mathrm{CF}_{3}\right)_{2} \mathrm{CHOH}$ and acetone, and the solution was poured into a large amount of $\mathrm{CH}_{3} \mathrm{OH} / \mathrm{H}_{2} \mathrm{O}(1 / 1, \mathrm{v} / \mathrm{v})$. The precipitated polymer was collected by filtration, washed several times with $\mathrm{CH}_{3} \mathrm{OH} / \mathrm{H}_{2} \mathrm{O}$, and dried at $40^{\circ} \mathrm{C}$ in vacuo for $6 \mathrm{~h}$.

\section{Preparation of Oligo(methyl crotonate)}

Oligomerization was initiated by adding $3.3 \mathrm{mmol}$ of 2 to a stirred solution of methyl crotonate $(10 \mathrm{mmol})$, $\mathrm{HgI}_{2}(0.096 \mathrm{mmol})$ and $\left(\mathrm{C}_{2} \mathrm{H}_{5}\right)_{3} \mathrm{SiI}(0.29 \mathrm{mmol})$ in $21 \mathrm{ml}$ $\mathrm{CH}_{2} \mathrm{Cl}_{2}$ at $-40^{\circ} \mathrm{C}$ under a dry nitrogen atmosphere. After $4 \mathrm{~h}$ the reaction was terminated with a small amount of $\mathrm{HCl} / \mathrm{CH}_{3} \mathrm{OH}$, and the oligomerization mixture was poured into $200 \mathrm{ml}$ of hexane. Hexane-insoluble polymer $(0.091 \mathrm{~g})$ and $\mathrm{HgI}_{2}$ were removed by filtration and washed thoroughly with hexane. The filtrate and washings were combined and evaporated to dryness to recover hexane-soluble oligomer $(0.715 \mathrm{~g})$.

The hexane-soluble oligomer was fractionated into the individual homologs from trimer to hexamer by a JASCO PU-980 chromatograph equipped with Shodex
SEC columns K-2001 $(20 \mathrm{~mm}$ i.d. $\times 300 \mathrm{~mm} \times 2$, maximum porosity $1.5 \times 10^{3}$ ) using $\mathrm{CHCl}_{3}$ as the eluent. Separation of stereoisomers in each fraction was performed on a normal-phase HPLC using Develosil 100-5 $(10 \mathrm{~mm}$ i.d. $\times 250 \mathrm{~mm} \times 2)$ as the stationary phase and mixtures of $n$-butyl chloride and acetonitrile as the mobile phase. The isomers were purified further by a reversed-phase HPLC using Develosil ODS-HG-5 (10 $\mathrm{mm}$ i.d. $\times 250 \mathrm{~mm}$ ) as the stationary phase and mixtures of $\mathrm{CH}_{3} \mathrm{OH} / \mathrm{H}_{2} \mathrm{O}$ (tetramer) or tetrahydrofuran $(\mathrm{THF}) / \mathrm{H}_{2} \mathrm{O}$ (hexamer) as the mobile phase at $40^{\circ} \mathrm{C}$.

\section{Measurements}

Chemical purity of the above-mentioned reagents was determined by using a Hewlett Packard 6890 gas chromatograph equipped with an HP-5 fused-silica capillary column $(0.32 \mathrm{~mm} \times 30 \mathrm{~m})$ and a flame-ionization detector.

Number-average molecular weight $\left(\bar{M}_{n}\right)$ was determined by vapor pressure osmometry (VPO) on a Hitachi 117 apparatus using toluene as the solvent at $60.0^{\circ} \mathrm{C}$. Size exclusion chromatography (SEC) was performed on a JASCO PU-980 chromatograph equipped with Polymer Laboratories SEC columns PLgel Mixed-D $\left(7.5 \mathrm{~mm} \times 300 \mathrm{~mm} \times 2\right.$, maximum porosity $\left.4 \times 10^{5}\right)$ and a JASCO RI-930 detector using $\mathrm{CHCl}_{3}$ as the eluent at $40^{\circ} \mathrm{C}$. Molecular weight was calibrated against standard PMMA samples.

Differential scanning calorimetry (DSC) was performed on a Seiko DSC6200R calorimeter at a heating rate of $10^{\circ} \mathrm{C} \mathrm{min} \min ^{-1}$

NMR spectra were recorded on a Varian Unity-INOVA 750 spectrometer in $\left(\mathrm{CF}_{3}\right)_{2} \mathrm{CHOH} / \mathrm{C}_{6} \mathrm{D}_{6}(95 / 5, \mathrm{v} / \mathrm{v})$ at $55^{\circ} \mathrm{C}$ or in $\mathrm{CDCl}_{3}$ at $35^{\circ} \mathrm{C}$. The strong resonances due to $\left(\mathrm{CF}_{3}\right)_{2} \mathrm{CHOH}$ were suppressed by the WET method. ${ }^{23}$

$\mathrm{X}$-Ray data were collected with a Rigaku AFC-7R automated four-circle diffractometer using graphitemonochromated Mo- $K_{\alpha}$ radiation $(200 \mathrm{kV}, 50 \mathrm{~mA})$. Crystal structures were solved by direct methods (MULTAN88). Positions of all non-hydrogen atoms were refined with anisotropic thermal parameters. Hydrogen atoms were placed in idealized positions and included in the structure refinement by the least-squares method using a TeXsan software package.

\section{RESULTS AND DISCUSSION}

\section{GTP of Methyl Crotonate under Various Conditions}

Polymerization of methyl crotonate was carried out with initiator 1 in the presence of $\mathrm{HgI}_{2}$ catalyst and $\left(\mathrm{CH}_{3}\right)_{3} \mathrm{SiI}$ co-catalyst in $\mathrm{CH}_{2} \mathrm{Cl}_{2}$. Table I shows the yield and molecular weight of poly(methyl crotonate) formed in the GTP. The temperature greatly affected the polymer yield, which can be seen in the results of polymerization for $24 \mathrm{~h}$ with a feed ratio of methyl crotonate to $\mathbf{1}$ $\left([M]_{0} /[1]_{0}\right)$ of $50 \mathrm{~mol} \mathrm{~mol}^{-1}$. The maximum yield was obtained at $-40^{\circ} \mathrm{C}$. The polymer obtained at $-40^{\circ} \mathrm{C}$ showed narrower molecular distribution $\left(\bar{M}_{w} / \bar{M}_{n}=1.21\right)$ than those obtained at 0 and $-20^{\circ} \mathrm{C}$. Initiator efficiency of the polymerization $(f)$ was also highest at $-40^{\circ} \mathrm{C}$. These results suggest that side reactions, probably selftermination by cyclization and O-to-C-silyl isomerization of propagating chain-ends, ${ }^{24,25}$ occur in the po- 
Table I. Polymerization of methyl crotonate with ketene trialkylsilyl acetal in the presence of $\mathrm{HgI}_{2}$ and iodotrialkylsilane in $\mathrm{CH}_{2} \mathrm{Cl}_{2}{ }^{\mathrm{a}}$

\begin{tabular}{|c|c|c|c|c|c|c|c|c|}
\hline \multirow{2}{*}{$\mathrm{R}_{3} \mathrm{SiI}$} & \multicolumn{2}{|c|}{ Initiator } & \multirow{2}{*}{$\frac{\text { Temp }}{{ }^{\circ} \mathrm{C}}$} & \multirow{2}{*}{$\frac{\text { Time }}{\mathrm{h}}$} & \multirow{2}{*}{$\frac{\text { Yield }}{\%}$} & \multirow{2}{*}{$\frac{\bar{M}_{n}}{10^{3}}$} & \multirow{2}{*}{$\frac{\bar{M}_{w}}{\bar{M}_{n}}$} & \multirow{2}{*}{$f^{\mathrm{b}}$} \\
\hline & & $\mathrm{mmol}$ & & & & & & \\
\hline \multirow[t]{8}{*}{$\left(\mathrm{CH}_{3}\right)_{3} \mathrm{SiI}$} & 1 & 0.20 & 0 & 24 & 31 & 3.4 & 1.44 & 0.42 \\
\hline & & 0.20 & -20 & 24 & 62 & 5.0 & 1.45 & 0.56 \\
\hline & & 0.20 & -40 & 24 & 78 & 5.1 & 1.21 & 0.77 \\
\hline & & 0.20 & -60 & 24 & 6 & 1.6 & 1.24 & 0.17 \\
\hline & & 0.10 & -40 & 24 & 41 & 5.1 & 1.22 & 0.70 \\
\hline & & 0.10 & -40 & 48 & 72 & 7.9 & 1.43 & 0.87 \\
\hline & & 0.10 & -40 & 96 & 85 & 8.9 & 1.55 & 0.92 \\
\hline & & $0.20^{\mathrm{c}}$ & -40 & 48 & 80 & 9.0 & 1.20 & 0.44 \\
\hline \multirow[t]{5}{*}{$\left(\mathrm{C}_{2} \mathrm{H}_{5}\right)_{3} \mathrm{SiI}$} & 2 & 0.20 & 0 & 24 & 83 & 4.9 & 1.18 & 0.85 \\
\hline & & 0.20 & -20 & 24 & 100 & 5.2 & 1.18 & 0.96 \\
\hline & & 0.20 & -40 & 24 & 72 & 3.8 & 1.21 & 0.95 \\
\hline & & 0.20 & -60 & 24 & 18 & 1.2 & 1.22 & 0.75 \\
\hline & & $0.05^{\mathrm{d}}$ & -20 & 96 & 71 & 20.0 & 1.66 & 0.71 \\
\hline \multirow[t]{4}{*}{$\left(n-\mathrm{C}_{3} \mathrm{H}_{7}\right)_{3} \mathrm{SiI}$} & 3 & 0.20 & 0 & 24 & 96 & 5.0 & 1.21 & 0.96 \\
\hline & & 0.20 & -20 & 24 & 99 & 5.7 & 1.12 & 0.87 \\
\hline & & 0.20 & -40 & 24 & 49 & 2.9 & 1.22 & 0.85 \\
\hline & & 0.20 & -60 & 24 & 14 & 1.0 & 1.20 & 0.70 \\
\hline
\end{tabular}

${ }^{\mathrm{a}}$ Methyl crotonate, $10 \mathrm{mmol} ; \mathrm{HgI}_{2}, 0.016 \mathrm{mmol} ; \mathrm{R}_{3} \mathrm{Sil}, 0.048 \mathrm{mmol}$; $\mathrm{CH}_{2} \mathrm{Cl}_{2}, 8 \mathrm{ml}$. The $\bar{M}_{n}$ and $\bar{M}_{w} / \bar{M}_{n}$ were determined by VPO and SEC, respectively. ${ }^{\mathrm{b}}$ Initiator efficiency: $f=$ [The total yield in mol of polymers $] /\left[\right.$ The amount in mol of initiator in feed]. ${ }^{\mathrm{c}}$ Methyl isocrotonate, $10 \mathrm{mmol} ; \mathrm{CH}_{2} \mathrm{Cl}_{2}, 5 \mathrm{ml}$. ${ }^{\mathrm{d}} \mathrm{CH}_{2} \mathrm{Cl}_{2}, 4 \mathrm{ml}$.
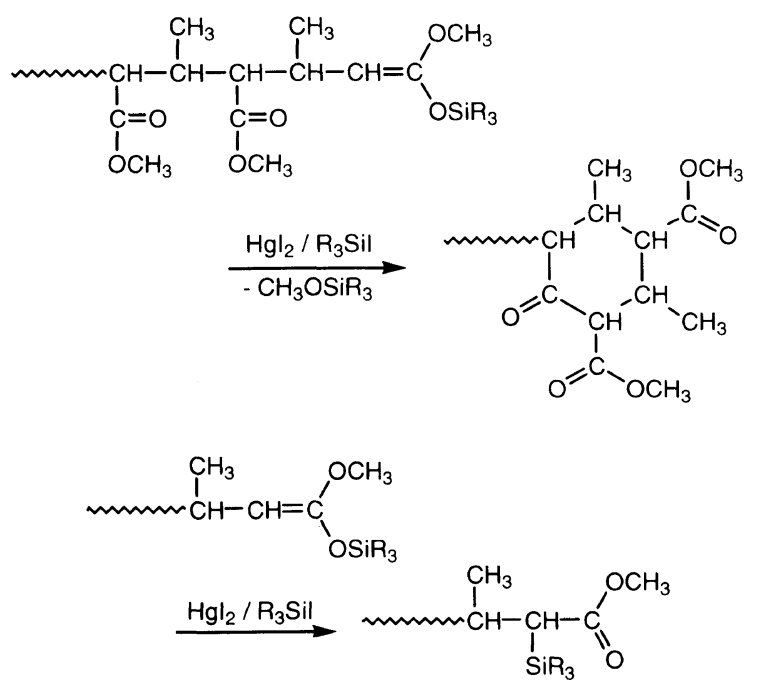

lymerizations at 0 and $-20^{\circ} \mathrm{C}$. When the polymerization was conducted at $-40^{\circ} \mathrm{C}$ with $[M]_{0} /[1]_{0}$ of 100 mol mol${ }^{-1}$, the yield and $\bar{M}_{n}$ of polymer increased slowly with time. $\bar{M}_{w} / \bar{M}_{n}$ and $f$ also increased with polymerization time, indicating slow-initiation characteristics of this polymerization.

Polymerization of methyl crotonate with $2 / \mathrm{HgI}_{2} /$ $\left(\mathrm{C}_{2} \mathrm{H}_{5}\right)_{3} \mathrm{SiI}$ was carried out in a similar manner (Table I). Polymer with a narrow molecular weight distribution $\left(\bar{M}_{w} / \bar{M}_{n} \leq 1.22\right)$ was obtained at any temperatures from 0 to $-60^{\circ} \mathrm{C}$. The polymerization at $-20^{\circ} \mathrm{C}$ proceeded quantitatively, and $f$ was close to unity (0.96). As shown in Figure $1, \bar{M}_{n}$ of polymer increased linearly with yield in the polymerization at $-20^{\circ} \mathrm{C}$. It is clear from these facts that the $2 / \mathrm{HgI}_{2} /\left(\mathrm{C}_{2} \mathrm{H}_{5}\right)_{3} \mathrm{SiI}$ system is superior to $1 / \mathrm{HgI}_{2} /\left(\mathrm{CH}_{3}\right)_{3} \mathrm{SiI}$ with regard to the livingness of polymerization. This can be ascribed to the higher stability of

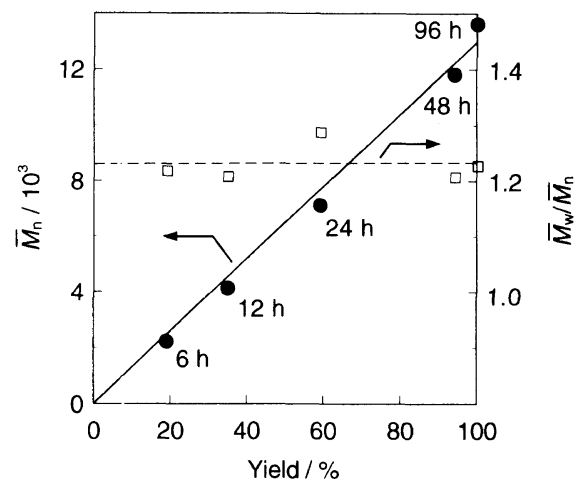

Figure 1. $\bar{M}_{n}(\boldsymbol{O})$ and $\bar{M}_{w} / \bar{M}_{n}(\square)$ plots against the polymer yield in GTP of methyl crotonate with $2 / \mathrm{HgI}_{2} /\left(\mathrm{C}_{2} \mathrm{H}_{5}\right)_{3} \mathrm{SiI}$ in $\mathrm{CH}_{2} \mathrm{Cl}_{2}$ at $-20^{\circ} \mathrm{C}$. Methyl crotonate, $10 \mathrm{mmol} ; 2,0.10 \mathrm{mmol} ; \mathrm{HgI}_{2}, 0.016 \mathrm{mmol}$; $\left(\mathrm{C}_{2} \mathrm{H}_{5}\right)_{3} \mathrm{SiI}, 0.048 \mathrm{mmol} ; \mathrm{CH}_{2} \mathrm{Cl}_{2}, 8 \mathrm{ml}$.

Table II. GTP of methyl crotonate with $1 / \mathrm{HgI}_{2} /$ $\left(\mathrm{CH}_{3}\right)_{3} \mathrm{Sil}$ in $\mathrm{CH}_{2} \mathrm{Cl}_{2}$ at $-40^{\circ} \mathrm{C}^{\mathrm{a}}$

\begin{tabular}{|c|c|c|c|c|}
\hline $\mathrm{HgI}_{2}$ & $\left(\mathrm{CH}_{3}\right)_{3} \mathrm{SiI}$ & Yield & $\bar{M}_{n}$ & $\bar{M}_{w}$ \\
\hline $\mathrm{mmol}$ & $\mathrm{mmol}$ & $\%$ & $10^{3}$ & $\bar{M}_{n}$ \\
\hline 0.016 & 0 & 0 & & \\
\hline 0.016 & 0.024 & 4 & 3.0 & 1.26 \\
\hline 0.016 & 0.048 & 78 & 5.1 & 1.21 \\
\hline 0.016 & 0.096 & 46 & 4.6 & 1.18 \\
\hline 0 & 0.048 & 0 & & \\
\hline 0.008 & 0.048 & 31 & 3.0 & 1.16 \\
\hline 0.032 & 0.048 & 95 & 6.2 & 1.33 \\
\hline
\end{tabular}

${ }^{\text {a }}$ Methyl crotonate, $10 \mathrm{mmol} ; \mathbf{1}, 0.20 \mathrm{mmol}$; time, $24 \mathrm{~h} ; \mathrm{CH}_{2} \mathrm{Cl}_{2}, 8 \mathrm{ml}$. The $\bar{M}_{n}$ and $\bar{M}_{w} / \bar{M}_{n}$ were determined by VPO and SEC, respectively.

$\left(\mathrm{C}_{2} \mathrm{H}_{5}\right)_{3} \mathrm{Si}$-acetals than $\left(\mathrm{CH}_{3}\right)_{3}$ Si-acetals. ${ }^{26}$ Polymerization with $[M]_{0} /[2]_{0}$ of $200 \mathrm{~mol} \mathrm{~mol}^{-1}$ for $96 \mathrm{~h}$ gave a polymer with $\bar{M}_{n}$ of $2.0 \times 10^{4}$. This polymer had a rather broad molecular weight distribution.

Side reactions in the GTP seem to be further suppressed by the use of $3 / \mathrm{HgI}_{2} /\left(n-\mathrm{C}_{3} \mathrm{H}_{7}\right)_{3} \mathrm{SiI}$ system. The polymerization with this system proceeded almost quantitatively even at $0^{\circ} \mathrm{C}$ and showed $f$ of 0.96 (Table I). On the other hand, in the polymerization at $-40^{\circ} \mathrm{C}$ where the side reactions appear to be negligible, the polymer yields in the polymerizations with $1 / \mathrm{HgI}_{2} /$ $\left(\mathrm{CH}_{3}\right)_{3} \mathrm{SiI}, \mathbf{2} / \mathrm{HgI}_{2} /\left(\mathrm{C}_{2} \mathrm{H}_{5}\right)_{3} \mathrm{SiI}$, and $\mathbf{3} / \mathrm{HgI}_{2} /\left(n-\mathrm{C}_{3} \mathrm{H}_{7}\right)_{3} \mathrm{SiI}$ for $24 \mathrm{~h}$ decreased in that order $(78,72$, and $49 \%$, respectively, see Table I). This indicates that the rate of polymerization decreases with increasing thermal stability of propagating chain-ends.

The GTP of methyl crotonate did not proceed without either $\mathrm{HgI}_{2}$ or iodotrialkylsilane (Table II). When 0.016 mmol of $\mathrm{HgI}_{2}$ was used in the polymerization, the maximum rate of polymerization was obtained in the presence of $0.048 \mathrm{mmol}$ of $\left(\mathrm{CH}_{3}\right)_{3} \mathrm{SiI}$. The use of $0.032 \mathrm{mmol}$ of $\mathrm{HgI}_{2}$ with $0.048 \mathrm{mmol}$ of $\left(\mathrm{CH}_{3}\right)_{3} \mathrm{SiI}$ caused further acceleration of polymerization with slight broadening of molecular weight distribution.

Not only $\mathrm{HgI}_{2}$ but also $\mathrm{ZnI}_{2}$ and $\mathrm{CdI}_{2}$ were found effective as catalysts in this GTP (Table III). All these catalysts belong to the iodides of the group 12 (2B) metals. $\mathrm{CdI}_{2}$ showed the highest catalytic activity in the GTP using 1 as the initiator and $\left(\mathrm{CH}_{3}\right)_{3} \mathrm{SiI}$ as the co-catalyst. In contrast, $\mathrm{HgI}_{2}$ was much more effective 
Table III. GTP of methyl crotonate with ketene trialkylsilyl acetals in the presence of metal iodide catalysts and iodotrialkylsilane co-catalysts in $\mathrm{CH}_{2} \mathrm{Cl}_{2}{ }^{\mathrm{a}}$

\begin{tabular}{|c|c|c|c|c|c|c|}
\hline \multirow{2}{*}{ Catalyst } & \multirow{2}{*}{ Initiator } & \multirow{2}{*}{$\mathrm{R}_{3} \mathrm{SiI}$} & Temp & Yield & $\bar{M}_{n}$ & $\bar{M}_{w}$ \\
\hline & & & ${ }^{\circ} \mathrm{C}$ & $\%$ & $10^{3}$ & $\bar{M}_{n}$ \\
\hline \multirow[t]{4}{*}{$\mathrm{ZnI}_{2}$} & \multirow[t]{2}{*}{1} & \multirow[t]{2}{*}{$\left(\mathrm{CH}_{3}\right)_{3} \mathrm{SiI}$} & -20 & 70 & 4.1 & 1.22 \\
\hline & & & -40 & 36 & 2.2 & 1.14 \\
\hline & \multirow[t]{2}{*}{2} & \multirow{2}{*}{$\left(\mathrm{C}_{2} \mathrm{H}_{5}\right)_{3} \mathrm{SiI}$} & -20 & Trace & & \\
\hline & & & -40 & Trace & & \\
\hline \multirow[t]{4}{*}{$\mathrm{CdI}_{2}{ }^{\mathrm{b}}$} & \multirow[t]{2}{*}{1} & \multirow{2}{*}{$\left(\mathrm{CH}_{3}\right)_{3} \mathrm{SiI}$} & -20 & 89 & 7.7 & 1.06 \\
\hline & & & -40 & 93 & 5.4 & 1.18 \\
\hline & \multirow[t]{2}{*}{2} & \multirow[t]{2}{*}{$\left(\mathrm{C}_{2} \mathrm{H}_{5}\right)_{3} \mathrm{SiI}$} & -20 & 42 & 2.7 & 1.19 \\
\hline & & & -40 & 14 & 1.3 & 1.17 \\
\hline \multirow[t]{4}{*}{$\mathrm{HgI}_{2}$} & \multirow[t]{2}{*}{1} & \multirow[t]{2}{*}{$\left(\mathrm{CH}_{3}\right)_{3} \mathrm{SiI}$} & -20 & 51 & 6.1 & 1.49 \\
\hline & & & -40 & 82 & 6.2 & 1.22 \\
\hline & \multirow[t]{2}{*}{2} & \multirow{2}{*}{$\left(\mathrm{C}_{2} \mathrm{H}_{5}\right)_{3} \mathrm{SiI}$} & -20 & 100 & 5.8 & 1.15 \\
\hline & & & -40 & 88 & 4.7 & 1.20 \\
\hline
\end{tabular}

${ }^{a}$ Methyl crotonate, $10 \mathrm{mmol}$; initiator, $0.20 \mathrm{mmol}$; catalyst, 0.016 mmol; $\mathrm{R}_{3}$ SiI, $0.048 \mathrm{mmol} ; \mathrm{CH}_{2} \mathrm{Cl}_{2}, 4 \mathrm{ml}$; time, $24 \mathrm{~h}$. The $\bar{M}_{n}$ and $\bar{M}_{w} / \bar{M}_{n}$ were determined by VPO and SEC, respectively. ${ }^{\mathrm{b}} \mathrm{A}$ part of $\mathrm{CdI}_{2}$ was insoluble in the polymerization mixture.

than $\mathrm{ZnI}_{2}$ and $\mathrm{CdI}_{2}$ when 2 and $\left(\mathrm{C}_{2} \mathrm{H}_{5}\right)_{3}$ SiI were employed in the polymerization. Further studies on the GTP of crotonates in the presence of $\mathrm{ZnI}_{2}$ and iodotrialkylsilanes will be reported in a forthcoming paper.

Poly(methyl crotonate)s obtained by the GTP showed no distinct glass transition nor melting point in the DSC measurements between -100 and $270^{\circ} \mathrm{C}$. Softening point of this material appears to be higher than its thermal degradation temperature in the atmosphere (onset, $c a$. $\left.280^{\circ} \mathrm{C}\right)$. The polymers prepared with $1 / \mathrm{HgI}_{2} /\left(\mathrm{CH}_{3}\right)_{3} \mathrm{SiI}$ were soluble in $\mathrm{CH}_{2} \mathrm{Cl}_{2}, \mathrm{CHCl}_{3}$, toluene, THF, and $\left(\mathrm{CF}_{3}\right)_{2} \mathrm{CHOH}$, while polymers prepared with $2 / \mathrm{HgI}_{2} /$ $\left(\mathrm{C}_{2} \mathrm{H}_{5}\right)_{3} \mathrm{SiI}$ and $3 / \mathrm{HgI}_{2} /\left(n-\mathrm{C}_{3} \mathrm{H}_{7}\right)_{3}$ SiI were soluble in the above solvents except toluene. This difference in solubility to toluene can arise from stereoregularity of the polymers. As reported previously, ${ }^{13,15}$ threodiisotactic and diheterotactic poly(methyl crotonate)s dissolve only in $\left(\mathrm{CF}_{3}\right)_{2} \mathrm{CHOH}$ whereas poly(methyl crotonate)s with low stereoregularities are soluble in every solvent mentioned above.

${ }^{1} \mathrm{H}$ NMR spectroscopy clearly showed that the stereostructure of poly(methyl crotonate)s prepared with GTP (Figures 2a and 2b) was different from those of threodiisotactic (Figure 2c), diheterotactic (Figure 2d), and atactic-like (Figure 2e) poly(methyl crotonate)s. Each of the $\beta-\mathrm{CH}_{3}$ and $\mathrm{OCH}_{3}$ resonances in Figures $2 \mathrm{a}$ and $2 \mathrm{~b}$ appears as a doublet, and their chemical shifts disagree with those of threodiisotactic or diheterotactic poly(methyl crotonate). These spectra also indicate that the polymer prepared with $2 / \mathrm{HgI}_{2} /\left(\mathrm{C}_{2} \mathrm{H}_{5}\right)_{3} \mathrm{SiI}$ (Figure $2 \mathrm{~b})$ has higher stereoregularity than that prepared with $\mathbf{1} / \mathrm{HgI}_{2} /\left(\mathrm{CH}_{3}\right)_{3} \mathrm{SiI}$ (Figure 2a). Polymers prepared with $3 / \mathrm{HgI}_{2} /\left(n-\mathrm{C}_{3} \mathrm{H}_{7}\right)_{3} \mathrm{SiI}$ showed spectra quite similar to Figure $2 b$.

\section{Stereostructure Determination by Oligomer Analysis}

In our previous studies, configurational determination of stereoregular poly(methyl crotonate)s was made by chromatographic separation of their low molecular weight homologs (trimer to octamer), followed by X-ray single crystal analysis of each individual homolog. ${ }^{1-15}$

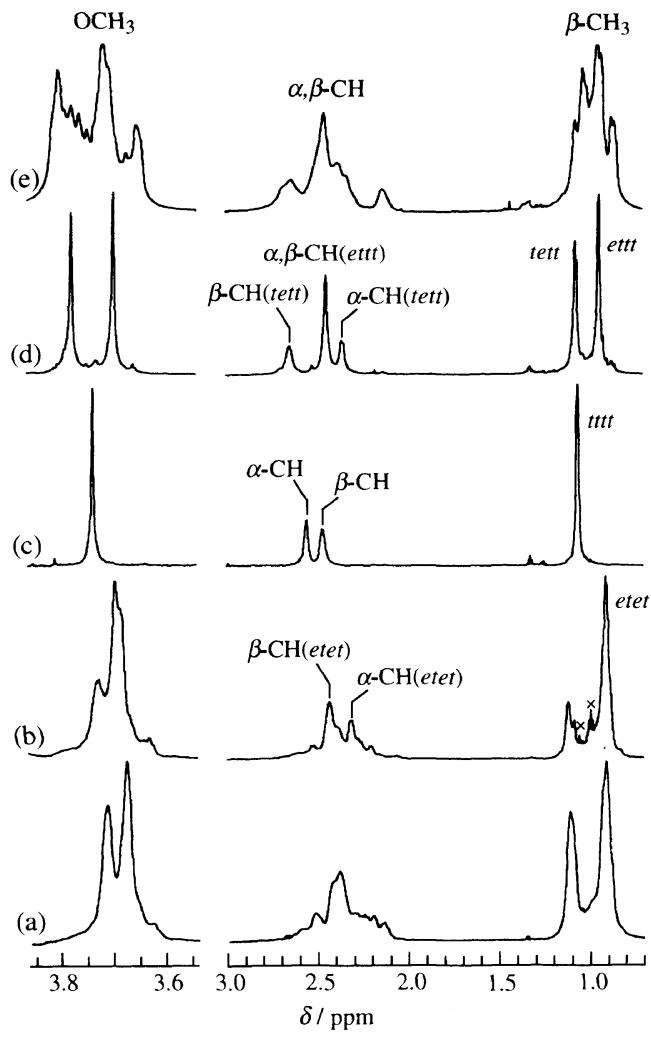

Figure 2. ${ }^{1} \mathrm{H}$ NMR spectra of poly(methyl crotonate)s prepared by the GTP with $1 / \mathrm{HgI}_{2} /\left(\mathrm{CH}_{3}\right)_{3} \mathrm{SiI}$ at $-40^{\circ} \mathrm{C}$ (a) and with $2 / \mathrm{HgI}_{2} /$ $\left(\mathrm{C}_{2} \mathrm{H}_{5}\right)_{3} \mathrm{Sil}$ at $-40^{\circ} \mathrm{C}$ (b). The spectra of highly threodiisotactic (c), highly diheterotactic (d), and atactic-like (e) poly(methyl crotonate)s are also shown. All spectra were measured in $\left(\mathrm{CF}_{3}\right)_{2} \mathrm{CHOH} / \mathrm{C}_{6} \mathrm{D}_{6}$ $(95 / 5 \mathrm{v} / \mathrm{v})$ at $55^{\circ} \mathrm{C}$ and $750 \mathrm{MHz}$. ( $\left.\times\right)$ Signals due to the end-groups.

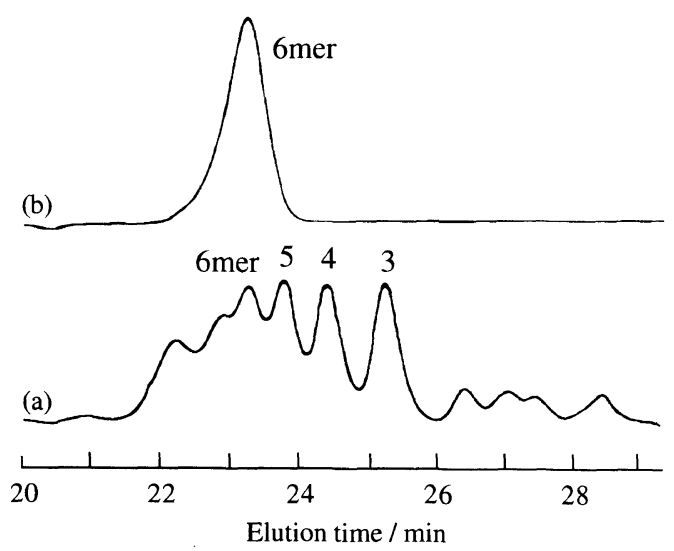

Figure 3. Size exclusion chromatograms of oligo(methyl crotonate) prepared by the GTP with $2 / \mathrm{HgI}_{2} /\left(\mathrm{C}_{2} \mathrm{H}_{5}\right)_{3} \mathrm{SiI}$ in $\mathrm{CH}_{2} \mathrm{Cl}_{2}$ at $-40^{\circ} \mathrm{C}$ (a) and of the hexamer isolated from the oligomer by $\mathrm{SEC}$ fractionation (b).

The same strategy has been applied to the stereostructure analysis of the poly(methyl crotonate) obtained by GTP.

Oligo(methyl crotonate) was prepared with $2 / \mathrm{HgI}_{2} /$ $\left(\mathrm{C}_{2} \mathrm{H}_{5}\right)_{3} \mathrm{SiI}\left([M]_{0} /[2]_{0}=3.3 \mathrm{~mol} \mathrm{~mol}^{-1}\right)$ in $\mathrm{CH}_{2} \mathrm{Cl}_{2}$ at $-40^{\circ} \mathrm{C}$. Figure 3 shows an SEC chromatogram of the oligomer together with that of the hexamer isolated from the oligomer by SEC fractionation. The hexamer fraction consisted of a highly predominant stereoisomer (diastereomeric purity $>69 \%$ ) and other minor stereoisomers, which can be seen in the ${ }^{1} \mathrm{H}$ NMR signals due to methoxy groups of the hexamers (Figure 4a). The 


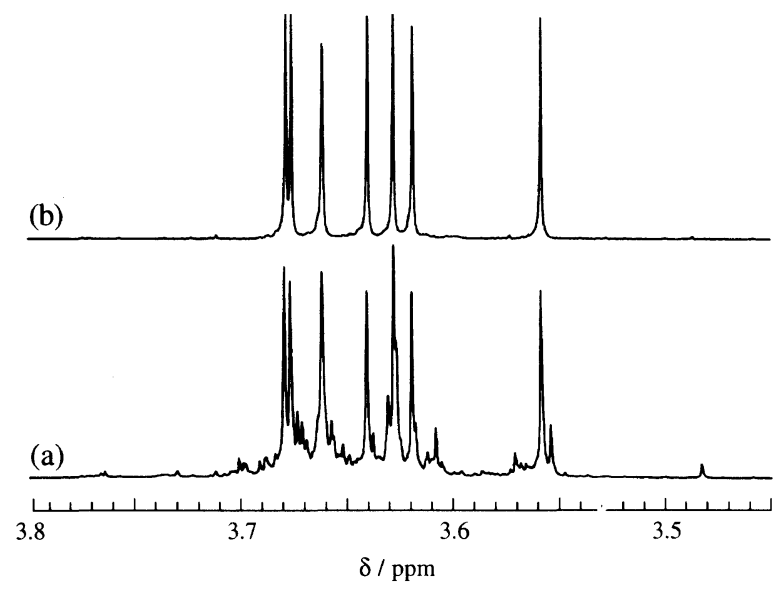

Figure 4. Methoxy proton resonances in $750 \mathrm{MHz}{ }^{1} \mathrm{H}$ NMR spectra of hexamers of methyl crotonate in $\mathrm{CDCl}_{3}$ at $35^{\circ} \mathrm{C}$. The diastereomer mixture obtained by SEC fractionation (a) and the predominant diastereomer separated from the mixture by normal-phase and reversed-phase HPLC procedures (b).

Table IV. Crystallographic data of disyndiotactic tetramer and hexamer of methyl crotonate ${ }^{a}$

\begin{tabular}{|c|c|c|}
\hline & Tetramer & Hexamer \\
\hline Molecular formula & $\mathrm{C}_{25} \mathrm{H}_{42} \mathrm{O}_{10}$ & $\mathrm{C}_{35} \mathrm{H}_{58} \mathrm{O}_{14}$ \\
\hline Formula weight & 502.60 & 702.83 \\
\hline Melting point $/{ }^{\circ} \mathrm{C}$ & $70.0-71.8$ & $140.1-141.3$ \\
\hline Crystal system & Triclinic & Triclinic \\
\hline Space group & $P \overline{\mathrm{I}}$ & $P \overline{\mathrm{I}}$ \\
\hline$a / \AA$ & $13.712(1)$ & $9.878(1)$ \\
\hline$b / \AA$ & $16.118(2)$ & $30.607(2)$ \\
\hline$c / \AA$ & $6.411(1)$ & $6.485(1)$ \\
\hline$\alpha / \operatorname{deg}$ & $99.92(1)$ & $92.83(1)$ \\
\hline$\beta / \mathrm{deg}$ & $98.48(1)$ & $101.25(1)$ \\
\hline$\gamma / \operatorname{deg}$ & $92.635(8)$ & $84.18(1)$ \\
\hline$V / \AA^{3}$ & $1376.7(3)$ & $1912.3(3)$ \\
\hline$Z$ & 2 & 2 \\
\hline$D_{\text {calcd }} / \mathrm{g} \mathrm{cm}^{-3}$ & 1.212 & 1.224 \\
\hline$\omega$-Scan width/deg & $1.68+0.30 \tan \theta$ & $1.00+0.30 \tan \theta$ \\
\hline $2 \theta$ Range/deg & $6.0<2 \theta<50.0$ & $6.0<2 \theta<55.0$ \\
\hline No. of unique data & 4852 & 9270 \\
\hline No. of obsd. data & $4007(I>3 \sigma(I))$ & $5669(I>5 \sigma(I))$ \\
\hline No. of variables & 316 & 442 \\
\hline$R$ & 0.046 & 0.098 \\
\hline$R_{w}$ & 0.041 & 0.068 \\
\hline
\end{tabular}

${ }^{\mathrm{a}} \omega$-Scan rate $8.0^{\circ} \mathrm{min}^{-1}$

presence of a single predominant isomer demonstrates high stereospecificity of the GTP, because the hexamer has 11 asymmetric carbon atoms in a molecule and therefore $1024\left(=2^{10}\right)$ diastereomers are theoretically possible. Purification of the hexamer fraction by normalphase and reversed-phase HPLC procedures gave a pure fraction of the predominant stereoisomer. An ${ }^{1} \mathrm{H}$ NMR spectrum of the isomer shows seven singlets with equal intensity due to the seven methoxy groups in a molecule (Figure 4b).

Single crystals were grown from a $\mathrm{CHCl}_{3} /$ hexane solution of this isomer at room temperature and subjected to X-ray crystallographic analysis. The crystallographic data are summarized in Table IV. Figure 5 shows the molecular structure determined by the X-ray analysis. The main chain of this hexamer adopts an extended all trans conformation, and the stereoregularity can easily be identified as a disyndiotactic structure. The relative
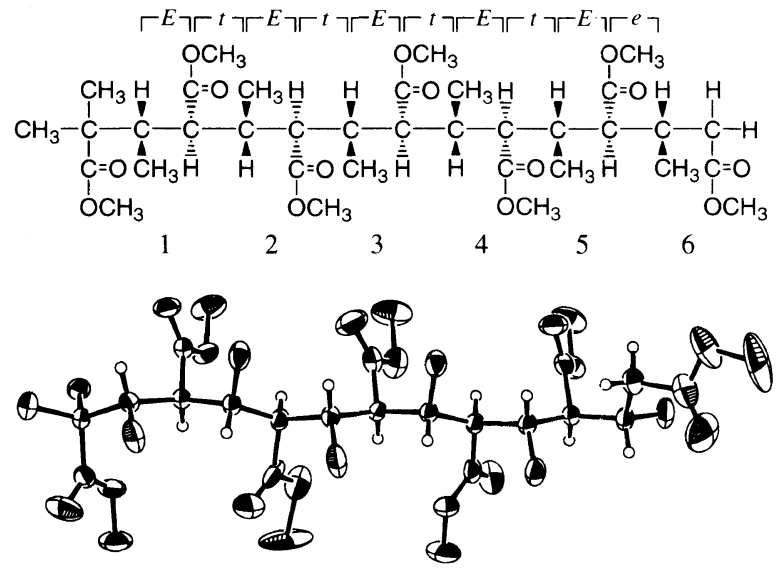

Figure 5. Crystal structure of disyndiotactic hexamer of methyl crotonate. Methyl hydrogen atoms are omitted for clarity.

configuration of 11 asymmetric carbon atoms in this hexamer is expressed by $(E t)_{4} E e$ according to the notations defined in our previous paper. ${ }^{15}$ The capital letters $E$ and $T$ denote the erythro and threo diads, respectively, in a monomer unit. The small letters $e$ and $t$ stand for the erythro and threo diads between adjacent monomer units. From the viewpoint of polymerization mechanism, $E$ and $T$ diads relate to the mode of double bond opening in a monomer molecule (trans opening or cis opening), while $e$ and $t$ diads relate to the way in which successive monomer molecules approach a growing chain-end. On the basis of the configurational structure of the hexamer, it can be concluded that disyndiotactic polymer chains are formed by the threo addition and trans opening mechanism in this stereospecific GTP.
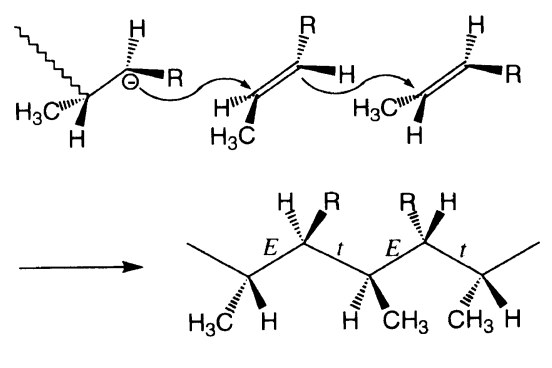

EtEt sequence

It should be noted that the disyndiotactic structure of this hexamer contains a configurational disorder at the chain-end; the structure is not $(E t)_{5}$ but $(E t)_{4} E e$.

In a similar manner as described above, single crystals suitable for X-ray analysis were obtained from the predominant stereoisomer of tetramer (diastereomeric purity $69 \%$ ). The molecular structure and crystallographic data are shown in Figure 6 and Table IV, respectively. This tetramer also had a disyndiotactic structure with a configurational disorder at the chain-end, namely the $(E t)_{2} E e$ structure. Though this configurational disorder must be related to the termination process in the polymerization, the reason for this curious phenomenon is presently unknown.

Figure 7a shows an ${ }^{1} \mathrm{H}$ NMR spectrum of the disyndiotactic hexamer. The assignments of the $\beta-\mathrm{CH}_{3}$, $\alpha-\mathrm{CH}$, and $\beta-\mathrm{CH}$ resonances and those of the terminal 

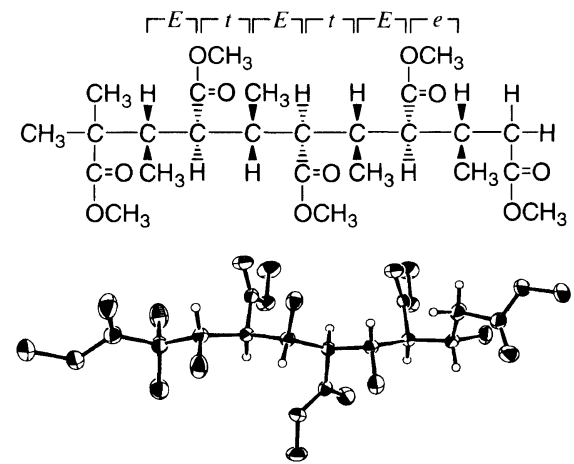

Figure 6. Crystal structure of disyndiotactic tetramer of methyl crotonate. Methyl hydrogen atoms are omitted for clarity.

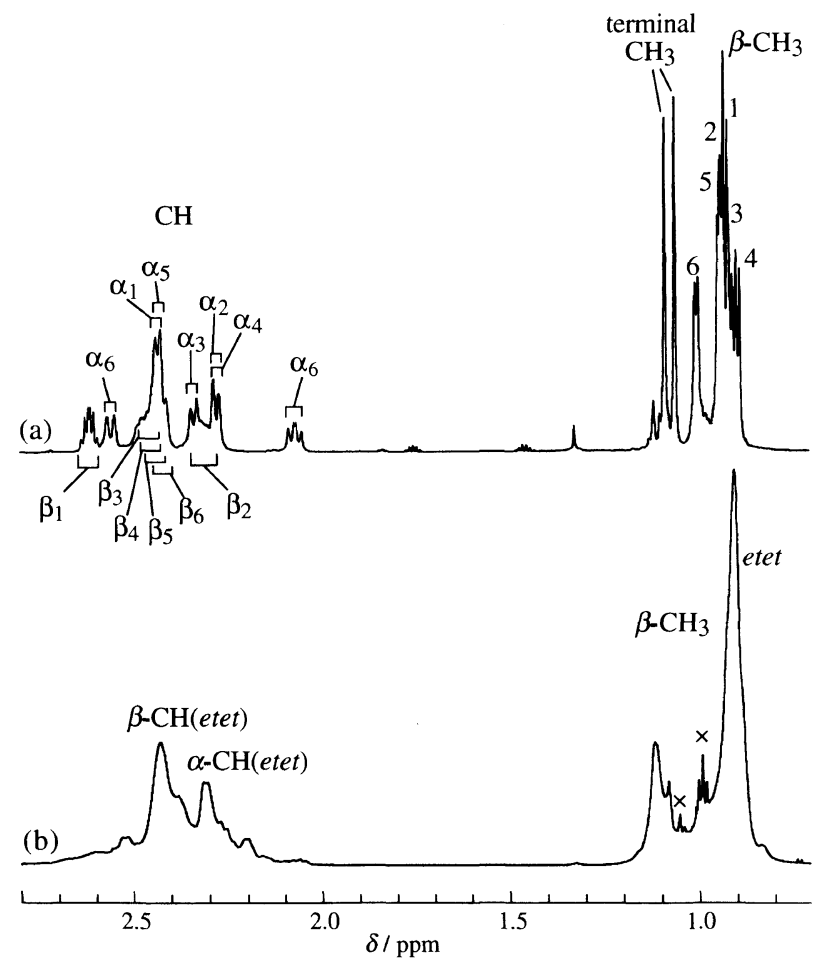

Figure 7. ${ }^{1} \mathrm{H}$ NMR spectra of disyndiotactic hexamer of methyl crotonate (a) and disyndiotactic poly(methyl crotonate) (b) measured in $\left(\mathrm{CF}_{3}\right)_{2} \mathrm{CDOD} / \mathrm{C}_{6} \mathrm{D}_{6}(95 / 5)$ at $55^{\circ} \mathrm{C}$ and $750 \mathrm{MHz}$. See Figure 5 for the numbering system of $\beta-\mathrm{CH}_{3}$ and $\mathrm{CH}$ groups in the hexamer. $(x)$ Signals due to the end-groups.

$\mathrm{CH}_{3}$ and $\alpha_{6}-\mathrm{CH}_{2}$ resonances were made by ${ }^{1} \mathrm{H} \mathrm{COSY}$ and HMQC experiments. All $\beta-\mathrm{CH}_{3}$ groups except for that of the sixth monomer unit showed NMR signals at 0.90 to $0.95 \mathrm{ppm}$. The chemical shift range agrees well with that of the main $\beta-\mathrm{CH}_{3}$ resonance of poly(methyl crotonate) prepared by the GTP $(0.92 \mathrm{ppm})$ (Figure 7b). This agreement allows us to assign the resonance at $0.92 \mathrm{ppm}$ to the $\beta-\mathrm{CH}_{3}$ group of poly(methyl crotonate) in etet sequence (EtEt and TeTe sequences in long polymer chains are indistinguishable by NMR and thus simply denoted as etet). The small resonance at $1.12 \mathrm{ppm}$ in Figure $7 \mathrm{~b}$ is attributable to the $\beta-\mathrm{CH}_{3}$ group at configurational defects in disyndiotactic poly(methyl crotonate). The broad peaks at 2.31 and $2.43 \mathrm{ppm}$ in Figure $7 \mathrm{~b}$ are assigned to the $\alpha-\mathrm{CH}$ and $\beta$ - $\mathrm{CH}$ groups in etet sequence, respectively, because the $\alpha-\mathrm{CH}$ protons in the second to forth monomer units of the hexamer $\left(\alpha_{2}\right.$, $\alpha_{3}, \alpha_{4}$ ) resonate at 2.27 to $2.33 \mathrm{ppm}$ and the $\beta$ - $\mathrm{CH}$ protons in the third to fifth monomer units $\left(\beta_{3}, \beta_{4}, \beta_{5}\right)$ resonate at 2.43 to $2.47 \mathrm{ppm}$.

\section{GTP of Methyl Isocrotonate}

Methyl isocrotonate, a geometrical isomer of methyl crotonate, also gave a polymer with narrow molecular weight distribution by GTP with $\mathbf{1} / \mathrm{HgI}_{2} /\left(\mathrm{CH}_{3}\right)_{3} \mathrm{SiI}$. The yield of polymer was $80 \%$ (Table I). This is the first example of methyl isocrotonate polymerization. Interestingly, ${ }^{1} \mathrm{H}$ NMR spectrum of this polymer was nearly the same as those of predominantly disyndiotactic poly(methyl crotonate)s obtained by the GTP of methyl crotonate with $1 / \mathrm{HgI}_{2} /\left(\mathrm{CH}_{3}\right)_{3}$ SiI. If the GTP of methyl isocrotonate proceeded in the threo addition-trans opening mechanism as in the case of methyl crotonate, threodiisotactic polymer should be formed and its NMR spectrum should be similar to Figure 2c, not to Figure $2 \mathrm{a}$.

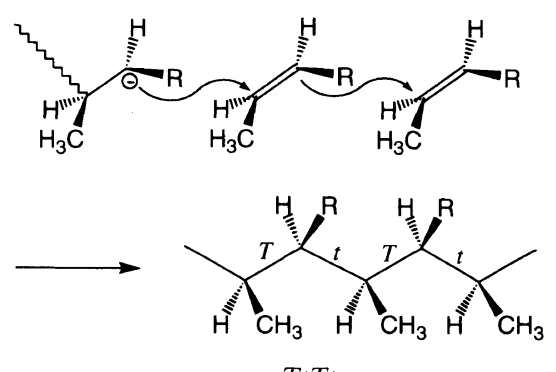

There are two possibilities that the disyndiotactic (etet) polymer is produced from methyl isocrotonate; (a) the threo addition-cis opening mechanism which results in the formation of EtEt sequence, and (b) the erythro addition-trans opening mechanism which results in the formation of $T e T e$ sequence. To distinguish these two stereoregulation mechanisms possible for the disyndiotactic polymerization of isocrotonate GTP, direct evidence on the structures of oligomers should be useful as demonstrated for the crotonate GTP, and the study is now under way.

\section{CONCLUSION}

The present work demonstrates that poly(methyl crotonate) can be prepared directly and efficiently by the GTP of methyl crotonate. With careful optimization of polymerization conditions, poly(methyl crotonate) with a molecular weight of 20000 is obtained. This GTP is disyndiotactic-specific and the specificity is varied by the structure of trialkylsilyl groups in the initiator and co-catalyst. Stereostructure analysis of low molecular weight homologs supplies detailed information about the stereoregulation process in the GTP.

Acknowledgments. The authors are grateful to the Venture Business Laboratory, Osaka University for assistance in performing high-field NMR experiments.

\section{REFERENCES}

1. K. Ute, T. Tarao, and K. Hatada, Polym. J., 29, 957 (1997).

2. I. B. Dicker, Polym. Prepr. (Am. Chem. Soc., Div. Polym. Chem.), 
29, 114 (1988).

3. I. B. Dicker, U. S. Patent, 4,732,955 (1988).

4. R. Zhuang and A. H. E. Müller, Macromolecules, 28, 8035 (1995).

5. R. Zhuang and A. H. E. Müller, Macromolecules, 28, 8043 (1995).

6. M. L. Miller and J. Skogman, J. Polym. Sci., Part A, 2, 4551 (1964).

7. R. K. Graham, J. E. Moore, and J. A. Powell, J. Appl. Polym. Sci., 11, 1797 (1967).

8. T. Tsuruta, T. Makimoto, and T. Miyazako, Makromol. Chem., 103, 128 (1967).

9. T. Tsuruta, T. Makimoto, and K. Tanabe, Makromol. Chem., 114, 182 (1968)

10. G. Natta, M. Peraldo, and M. Farina, Belg. Patent, 599,833 (1961).

11. A. Matsumoto, A. Horie, and T. Otsu, Polym. J., 23, 211 (1991).

12. K. Ute, T. Asada, Y. Nabeshima, and K. Hatada, Polym. Bull, 30, 171 (1993).

13. K. Ute, T. Asada, Y. Nabeshima, and K. Hatada, Macromolecules, 26, 7086 (1993).

14. K. Ute, T. Asada, Y. Nabeshima, and K. Hatada, Acta Polym., 46, 458 (1995)

15. K. Ute, T. Asada, and K. Hatada, Macromolecules, 29, 1904
(1996).

16. Y. Isono, M. Kawai, T. Kazama, and T. Takeuchi, Polymer, 35, 441 (1994).

17. T. Kitano, T. Fujimoto, and M. Nagasawa, Macromolecules, 7, 719 (1974).

18. Z. Hongmin and H. Yuanxue, Polym. Mater. Sci. Eng., 11, 30 (1995).

19. C. Rappe, Org. Synth., 53, 123 (1973); Acta Chem. Scand., 17, 2766 (1963).

20. C. Ainsworth, F. Chen, and Y.-N. Kuo, J. Organomet. Chem., 46, 59 (1972).

21. R. E. Ireland, R. H. Mueller, and A. K. Willard, J. Am. Chem. Soc., 98, 2868 (1976).

22. A. Kunai, T. Sakurai, E. Toyoda, M. Ishikawa, and Y. Yamamoto, Organometallics, 13, 3233 (1994).

23. R. J. Ogg, P. B. Kingsley, and J. S. Taylor, J. Magn. Reson., Ser. $B$, 104, 1 (1994).

24. W. J. Brittain and I. B. Dicker, Polym. Int., 30, 101 (1993).

25. W. J. Brittain and I. B. Dicker, Makromol. Chem., Macromol. Symp., 67, 373 (1993).

26. L. H. Sommer, "Stereochemistry, Mechanism and Silicon," McGraw-Hill, New York, N.Y., 1965, p 127. 